\title{
KATA-KATA KANSEI PADA PRODUK BERBASIS BUDAYA UNTUK PEMENUHAN KEBUTUHAN MASLOW
}

\author{
Ratih Setyaningrum \\ Progran Studi Teknik Industri \\ Fakultas TeknikUniversitas Dian Nuswantoro \\ Email:ratihha@gmail.com \\ I.G. Bagus Budi Dharma \\ Jurusan Teknik Mesin dan Industri \\ Fakultas TeknikUniversitas Gadjah Mada \\ Heddy Shri Ahimsa-Putra \\ Jurusan Antropologi, Fakultas Ilmu Budaya \\ Universitas Gadjah Mada
}

\begin{abstract}
Cultural aspect is not a priority within a product design and development process in Indonesia. On the other hand, cross culture products have success in the global market. That product is included in each Maslow level. Cultural aspect in product design is applied with a semantics, such as kansei words. The purpose of the research is to identify culture products and kansei words based on Maslow needs. The research stage begins with mapping culture products based on Maslow needs and determining kansei words. The result of this research is a classification of kansei words. It is used to guide product development. Product development based on Maslow needs is one strategy to attract consumers. Therefore, product development and diversification product had met the needs of Maslow.
\end{abstract}

Keywords: Maslow needs, Product, Culture, Kansei word

\begin{abstract}
ABSTRAK
Aspek budaya belum diprioritaskan dalam proses perancangan dan pengembangan produk di Indonesia. Padahal produk cross-culture sukses di pasar global.Produk tersebut tersebar di setiap jenjang (level) Maslow.Aspek budaya dalam suatu produk dituangkan dalam bentuk semantik menggunakan kata kansei.Penelitian ini memiliki tujuan antara lain mengidentifikasi produk berorientasi budaya disetiap level maslow dan menentukan kata-kata kansei pada produk tersebut. Tahapan penelitian diawali dengan memetakan produk budaya sesuai jenjang hirarki Maslow dan mengkaji referensi penelitian kansei. Proses berikutnya menentukan kata kansei dan mengklasifikasikannya sesuai jenjang kebutuhan Maslow. Luaran pengolahan data berupa klasifikasi kata kansei.Hasil klasifikasi kata kansei dapat digunakan sebagai acuan pengembangan produk.Pengembangan produk berdasarkan kebutuhan Maslow merupakan sebuah strategi untuk menarik konsumen. Oleh karena itu, pengembangan produk dan difersifikasi produk perlu diarahkan menuju jenjang kebutuhan Maslow.
\end{abstract}

Kata Kunci: Kebutuhan Maslow, Produk, Aspek Budaya, Kansei. 


\section{PENGANTAR}

Berbagai macam produk dipasarkan di Indonesia, baik berupa produk kebutuhan dasar (basic need) maupun kebutuhan level atas (meta needs). Indonesia merupakan pangsa pasar yang potensial. Indonesia memiliki jumlah penduduk yang besar dan memiliki keberagaman kebudayaan.Akan tetapi, produk berorientasi budaya belum begitu menonjol sehingga perlu pengembangan produk berbasis budaya Indonesia. Produk berbasis budaya dihasilkan dengan melibatkan aspek budaya Indonesia dalam proses perancangan dan pengembangan produk sehingga akan diperoleh produk yang berkarakter budaya masyarakat Indonesia.

Aspek budaya pada suatu produk dapat dituangkan dalam bentuk semantik berupa kata kansei. Produk dengan kata kansei tertentu akan mampu mengekspresikan karakter budaya disuatu masyarakat. Dalam rangka hal tersebut, penelitian awal ini dilakukan untuk mengidentifikasi produk budaya yang berkembang dan mengidentifikasi kata kansei yang mampu mengekspresikan kebutuhan konsumen. Salah satu cara mengekspresikan keinginan manusia dengan menggunakan metode kansei engineering (kata kansei).Kata kansei merupakan kata yang digunakan untuk menerjemahkan perasaan psikologis manusia menjadi parameter desain sebuah produk.

Berdasarkan hal tersebut diatas, perumusan masalah dalam penelitian ini sebagai berikut: (1)Bagaimana pengelompokan produk berorientasi budaya berdasarkan pemenuhan kebutuhan Maslow. (2) Apa sajakah kata kansei produk berorientasi budaya yang digunakan untuk memenuhi kebutuhan pada jenjang hirarki Maslow. (3) Bagaimana pengelompokkan kata kansei suatu produk yang sesuai dengan jenjang hirarki Maslow.

Kansei Enginering merupakan sebuah metode menerjemahkan citra (image) konsumen atau perasaan konsumen menjadi komponen desain yang riil menurut Naga- machi dan Mitsuo dalam Gunaady (2011). Penerapan kansei enginering digunakan dalam beberapa penelitian antara lain Jiao (2006) menerapkan kansei mining, Hasio dan Wang (1998) menggabungkan kansei dan artifisial intelegence dalam perancangan produk. Scuttle (2005) mengaplikasikan kansei engineering system dan Hsu (2000) menggabungkan kansei dengan semantic differensial untuk menangkap persepsi pengguna dan desainer.

Kebutuhan dasar Maslow berupa makanan juga mampu diidentifikasi pencitraannya menggunakan kansei. Hal tersebut dilakukan oleh Ueda dan Sano (2008), yang menghasilkan tujuh axis chart diagram yang mampu dimodelkan. Nagamachi dan Noor (2008) mengaplikasikan semantic differensial dan kansei untuk perancangan website pakaian. Penelitian tersebut menghasilkan 40 kata kansei yang mendeskripsikan emosi pengguna.

Selain kebutuhan sandang dan makanan, produk kursi, mobil dan handphone juga telah dianalis menggunakan metode kansei. Penelitian yang dilakukan Hasio dan Chen (1997) melakukan perancangan kursi menggunakan kansei dan menghasilkan 27 kata kansei.Sejalan dengan penelitian tersebut diatas, Gunaady (2011) melakukan perancangan kursi roda khusus pada lansia dan menghasilkan 14 pasang kata kansei yang diterapkan pada spesifikasi produk kursi roda lansia.

Hasio dan Wang (1998) mengembangkan desain mobil menggunakan katakansei dan didapatkan 15 kata kansei.Sedangkan produk handphone merupakan produk yang paling sering diteliti menggunakan metode kansei. Salah satunya dilakukan oleh Jiao (2006) dan Chen dan Hiu (2007) yang menghasilkan 27 kata kansei.

Para ahli antropologi berpendapat bahwa kebudayaan tersebut memiliki aspek atau dimensi, dan terdiri dari unsur-unsur. Berbeda dengan Koentjaraningrat dan ahli antropologi lainnya. Ahimsa-Putra (2013) berpendapat bahwa kebudayaan memiliki empat aspek 
atau wujud. Berturut-turut dari yang konkret ke yang abstrak, empat aspek tersebut sebagai berikut: (a) aspek fisik atau budaya material; (b) aspek perilaku atau budaya perilaku; (c) aspek kebahasaan atau bahasa, dan (d) aspek gagasan atau budaya pengetahuan.

Wujud atau aspek material kebudayaan berupa misalnya benda-benda, mulai dari yang kecil-kecil seperti jarum, kancing baju, hingga bangunan yang besar-besar, seperti gedung dengan puluhan lantai, candi, atau bahkan berupa kawasan. Aspek perilaku kebudayaan berupa misalnya perilakuperilaku, aktivitas bersama, berbagai interaksi sosial, relasi sosial, lapisan, dan golongan sosial. Aspek kebahasaan kebudayaan berupa bahasa, atau lebih konkret lagi berupa istilah-istilah, ungkapan-ungkapan, peribahasa, nyanyian rakyat, mitos, legenda, dan sebagainya. Aspek gagasan berupa pengetahuan, gagasan-gagasan kolektif, seperti pandangan hidup, nilai-nilai, normanorma, dan aturan-aturan.

Maslow menyusun teori motivasi manusia, dimana variasi kebutuhan manusia dipandang tersusun dalam bentuk hirarki atau berjenjang. Setiap jenjang kebutuhan dapat dipenuhi hanya jenjang sebelumnya telah (relatif) terpuaskan. Jadi kebutuhan fisiologis harus terpuaskan lebih dahulu sebelum muncul kebutuhan rasa aman. Sesudah kebutuhan fisiologis harus terpuaskan lebih dahulu sebelum muncul kebutuhan rasa aman. Sesudah kebutuhan fisiologis dan rasa aman terpuaskan, baru muncul kebutuhan kasih sayang, begitu seterusnya sampai kebutuhan dasar terpuaskan baru akan muncul kebutuhan meta. Tabel 1 menjelaskan jenjang kebutuhan Maslow yang terdiri dari Physiological needs, Safety needs, Love needs/Belongness, Esteem needs dan Self actualization needs. Pemenuhan kebutuhan berjenjang dari kebutuhan dasar (basic) hingga ke self actualization.

Tabel 1. Produk Berdasarkan Hirarki Kebutuhan Maslow

\begin{tabular}{|c|c|c|}
\hline \multicolumn{2}{|r|}{ JenjangNeeds } & \multirow{2}{*}{$\begin{array}{l}\text { Produk } \\
\text { Produk kreatif dan inovatif dan atau produk yang memiliki nilai } \\
\text { kemanfaatan tinggi bagi kemanusiaan. Contoh:alat transportasi yang } \\
\text { dimodifikasi dengan desain yang lebih menarik. }\end{array}$} \\
\hline 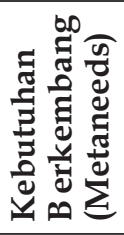 & $\begin{array}{l}\text { Selfactualization } \\
\text { needs (Metaneeds) }\end{array}$ & \\
\hline \multirow{4}{*}{ 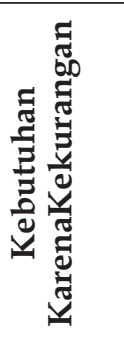 } & Esteemneeds & $\begin{array}{l}\text { Produk-produk dengan tingkat teknologi canggih, memiliki unsur } \\
\text { budaya kental dan bersifat unik. Contoh:lamborghini, keris, handphone } \\
\text { transparant,dll }\end{array}$ \\
\hline & $\begin{array}{l}\text { Love needs/ } \\
\text { Belonging-ness }\end{array}$ & $\begin{array}{l}\text { Produk untuk pemenuhan kebutuhan sosial dan familiarity, seperti alat } \\
\text { komunikasi, alat transportasi. }\end{array}$ \\
\hline & Safetyneeds & $\begin{array}{l}\text { Produk yang memiliki nilai keamanan/perlindungan misalnya: rumah } \\
\text { dan home appliances, }\end{array}$ \\
\hline & Physiological needs & Produk untuk kebutuhan fisik berupa makanan, minuman, dan pakaian. \\
\hline
\end{tabular}

Sumber: Maslow, 1970.

Jenjang hirarki Maslow seperti pada Tabel 1 menunjukkan bahwa kebutuhan dasar (basic needs) terdiri dari 4 level yaitu physiological need, safety need, love needs/belonging-ness, esteem needs. Setelah kebutuhan dasar terpenuhi akan menuju pada level metaneeds yaitu self actualization.

\section{Metode}

Tahapan diawali dengan menentukan jenjang/level kebutuhan Maslow, berikutnya mengidentifikasi produk yang tergolong pada setiap level Maslow. Produk tersebut akan dijabarkan sesuai unsur budaya yang dominan. Bersamaan dengan itu perlu dikaji 
literatur tentang kata kansei yang digunakan untuk memenuhi kebutuhan Maslow. Luaran proses tersebut diatas akan digunakan untuk menentukan kata kansei kemudian menggolongkan berdasarkan level hirarki Maslow. Secara lengkap tahapan penelitian ditampilkan Gambar 1 berikut ini.

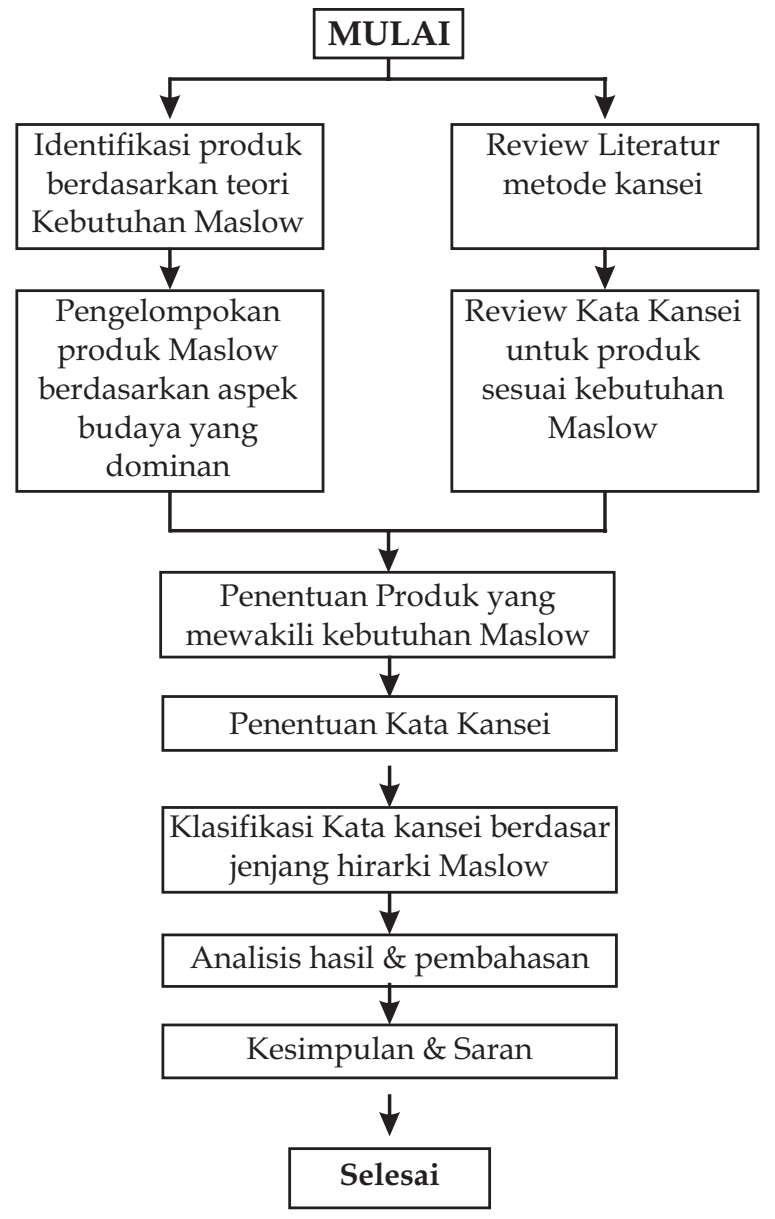

Gambar 1. Tahapan Penelitian

Penelitian ini diawali dengan melakukan reviewliterature penelitian yang menggunakan metode kansei.Kemudian kata-kata kansei pada setiap produk dikelompokkan berdasar jenjang hirarki Maslow.Bersamaan dengan itu dilakukan identifikasi produk berdasarkan teori Maslow.Kemudian produk pada setiap jenjang Maslow diklasifikasikan berdasarkan aspek budaya yang dominan. Luaran yang berupa kata kansei berdasarkan Maslow akan dipetakan berdasarkan aspek budaya yang dominan,sehingga akan terklasifikasi kata kansei yang telah berada pada setiap jenjang Maslow. Tahap akhir berupa analisis dan pembahasan dan rekomendasi.

\section{PEMBAHASAN}

Kebutuhan manusia menurut Maslow digolongkan berbentuk hirarki yang berjenjang. Pemenuhan kebutuhan pada jenjang dasar tercapai, maka akan menuju ke jenjang diatasnya begitu seterusnya. Klasifikasi kebutuhan produk berdasarkan hirarki Maslow dapat digabungkan dengan klasifikasi produk ditinjau dari aspek budaya.

Penggolongan aspek budaya meliputi materi (fisik produk), perilaku (kebiasaan pengguna), bahasa (istilah) dan pengetahuan (ide dasar produk).Tabel 2 dibawah ini menjelaskan contoh produk yang berada pada setiap jenjang Maslow yang diidentifikasi berdasarkan aspek budaya yang dominan. Penentuan klasifikasi berdasarkan empat aspek budaya yaitu materi, perilaku, bahasa, dan ide gagasan.Tabel 2 diperoleh dengan melakukan observasi produk yang beredar di pasar Indonesia kemudian diklasifikasikan kedalam empat aspek budaya.Tabel 2 menunjukkan bahwa setiap produk merupakan produk budaya dengan dominasi aspek budaya tertentu.Jenis produk makanan dan minuman yang dominan aspek budaya materi yaitu produk donat berbahan kentang atau minuman karbonasi. Sedangkan produk makanan ringan dengan berbagai level kepedasan merupakan produk yang berlatar belakang aspek budaya perilaku. Bahkan saat ini menjadi trenmakanan dengan level kepedasan bertingkat. Aspek bahasa/istilah pada produk digunakan sebagai jargon sebuah makanan agar lebih dikenal masyarakat. Sebagai contoh, apabila mendengar jargon "think different", masyarakat akan mengerti bahwa itu produk Apple. Beberapa produk juga sangat populer karena ide dan sejarah munculnya makanan seperti produk makanan dengan merek starbucks.

Pada Tabel 2 produk akan diklasifikasikan sesuai aspek budaya yang dominan. 
Tabel 2. Produk dominan aspek budaya

\begin{tabular}{|c|c|c|c|c|c|c|c|c|c|}
\hline \multirow[b]{2}{*}{$\sum_{\infty}^{\overleftarrow{c}}$} & \multicolumn{9}{|c|}{ Jenis Produk } \\
\hline & 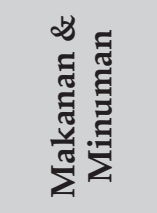 & ฐ̃ & 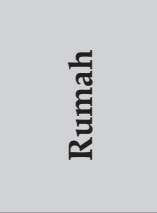 & 党 & 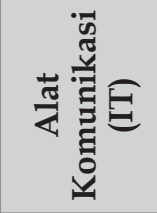 & 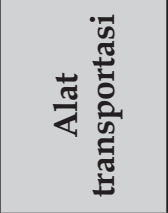 & 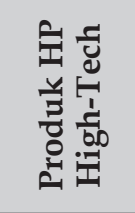 & 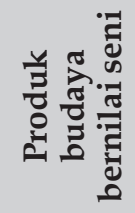 & 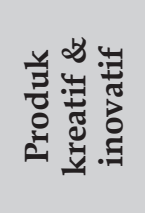 \\
\hline 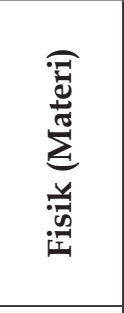 & $\begin{array}{l}\text { Donat } \\
\text { kentang, } \\
\text { Minuman } \\
\text { berion } \\
\text { karbonasi }\end{array}$ & $\begin{array}{l}\text { Model } \\
\text { \& Motif } \\
\text { pakaian } \\
\text { Batik, } \\
\text { Sorjan }\end{array}$ & $\begin{array}{l}\text { Rumah } \\
\text { Joglo } \\
\text { (kayu } \\
\text { jati), } \\
\text { rumah } \\
\text { Honai di } \\
\text { papua }\end{array}$ & $\begin{array}{l}\text { Kompor } \\
\text { gas dengan } \\
\text { tabung } \\
\text { safety }\end{array}$ & $\begin{array}{l}\text { Tablet } \\
\text { dileng- } \\
\text { kapi key- } \\
\text { board }\end{array}$ & $\begin{array}{l}\text { Mobil } \\
\text { warna } \\
\text { putih } \\
\text { menjadi } \\
\text { trend }\end{array}$ & $\begin{array}{l}\text { HP } \\
\text { berlapis } \\
\text { emas }\end{array}$ & $\begin{array}{l}\text { Keris, } \\
\text { patung }\end{array}$ & $\begin{array}{l}\text { Mobil } \\
\text { kayu } \\
\text { Sepatu } \\
\text { unik, } \\
\text { Radio } \\
\text { kayu, } \\
\text { sepatu } \\
\text { kayu,dll } \\
\end{array}$ \\
\hline 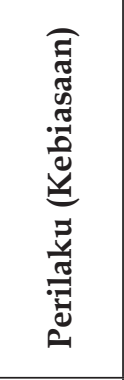 & $\begin{array}{l}\text { Makanan } \\
\text { ringan } \\
\text { dengan } \\
\text { berbagai } \\
\text { level } \\
\text { pedas,exp } \\
\text { ma'ici }\end{array}$ & $\begin{array}{l}\text { Rok } \\
\text { Jarik } \\
\text { kebaya, } \\
\text { pakaian } \\
\text { motif } \\
\text { Dayak } \\
\& \\
\text { Papua }\end{array}$ & $\begin{array}{l}\text { Rumah } \\
\text { minimalis. } \\
\text { Feature } \\
\text { yang } \\
\text { ditambah- } \\
\text { kan } \\
\text { Ruang } \\
\text { sholat, } \\
\text { toilet } \\
\text { duduk }\end{array}$ & $\begin{array}{l}\text { Tempat } \\
\text { tidur } \\
\text { tingkat } \\
\text { (bersusun), } \\
\text { Magic com } \\
\text { dilengkapi } \\
\text { timer }\end{array}$ & $\begin{array}{l}\text { Hand- } \\
\text { phone } \\
\text { dengan } \\
\text { fasilitas } \\
\text { TV, } \\
\text { internet } \\
\text { (social) }\end{array}$ & \begin{tabular}{|l|} 
MPV \\
(multi \\
Purpose \\
Vehicle), \\
Motor bak \\
terbuka \\
beroda \\
tiga.
\end{tabular} & $\begin{array}{l}\text { HP } \\
\text { flexible/ } \\
\text { curve }\end{array}$ & Lukisan & $\begin{array}{l}\text { Furniture } \\
\text { multi- } \\
\text { fungsi }\end{array}$ \\
\hline 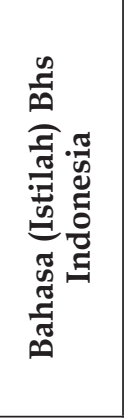 & $\begin{array}{l}\text { Quaker } \\
\text { Oat } \\
\text { (Cintai } \\
\text { Hidup } \\
\text { cintai jan- } \\
\text { tungmu) } \\
\text { Sosis } \\
\text { So Nice } \\
\text { (SMS), }\end{array}$ & $\begin{array}{l}\text { Lea } \\
\text { Jeans } \\
\text { (More } \\
\text { than } \\
\text { just } \\
\text { denim) }\end{array}$ & $\begin{array}{l}\text { Real } \\
\text { estate, } \\
\text { Kondomi- } \\
\text { nium } \\
\text { (aparte- } \\
\text { ment), } \\
\text { town- } \\
\text { house. }\end{array}$ & $\begin{array}{l}\text { Toshiba } \\
\text { (Leading } \\
\text { Inno- } \\
\text { vation), } \\
\text { LG (life's } \\
\text { Good), } \\
\text { Philips } \\
\text { (terus } \\
\text { terang, } \\
\text { terang } \\
\text { terus) }\end{array}$ & $\begin{array}{l}\text { Nokia } \\
\text { (Conec- } \\
\text { ting } \\
\text { People), } \\
\text { Apple } \\
\text { (Think } \\
\text { Different) }\end{array}$ & \begin{tabular}{|l|} 
Honda \\
(One \\
Heart), \\
Ertiga \\
(Mengerti \\
Keluarga)
\end{tabular} & $\begin{array}{l}\text { High } \\
\text { tech, } \\
\text { High } \\
\text { cost } \\
\text { Branded }\end{array}$ & $\begin{array}{l}\text { Artistik } \\
\text { Warisan } \\
\text { Budaya } \\
\text { Indo- } \\
\text { nesia }\end{array}$ & $\begin{array}{l}\text { Luxu- } \\
\text { rious, } \\
\text { Ama- } \\
\text { zing, } \\
\text { unik, } \\
\text { kreatif }\end{array}$ \\
\hline 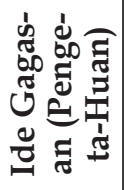 & Starbucks & $\begin{array}{l}\text { Pakaian } \\
\text { kertas, } \\
\text { resis- } \\
\text { tant api } \\
\text { dan air }\end{array}$ & $\begin{array}{l}\text { Rumah } \\
\text { pohon, } \\
\text { rumah } \\
\text { bola }\end{array}$ & $\begin{array}{l}\text { Fuzzy logic } \\
\text { LG home } \\
\text { appliances }\end{array}$ & $\begin{array}{l}\text { Produk } \\
\text { Teknologi } \\
\text { Apple }\end{array}$ & $\begin{array}{l}\text { Mobil } \\
\text { Hibrid, } \\
\text { Mobil } \\
\text { listrik,dll. }\end{array}$ & $\begin{array}{l}\text { Hand- } \\
\text { phone } \\
\text { trans- } \\
\text { paran }\end{array}$ & $\begin{array}{l}\text { Guci } \\
\text { Antik }\end{array}$ & \\
\hline
\end{tabular}

Pada Tabel 3 ditunjukkan bahwa produk diciptakan dan dikembangkan berdasarkan pemenuhan jenjang Maslow.Produk handphone untuk pemenuhan fisiogis hanya memiliki fungsi utama untuk telephone dan sms. Namun pada jenjang berikutnya, terdapat nilai tambah yang dikembangkan. Saat ini, ada produk handphone yang tahan air yang termasuk safety needs. Produk handphone yang dilengkapi fasilitas interaksi sosial juga digemari masyarakat. Untuk kalangan tertentu cenderung memilih produk handphone yang tergolong esteem needs yaitu handphone berlapis emas yang memiliki harga tinggi. Bahkan produk handphone unik dan kreatif juga hadir meramaikan pasar dunia. Hal tersebut menunjukkan bahwa produsen melakukan diferensiasi produk berdasar pada jenjang Maslow, mengingat kebutuhan manusia bertingkat sesuai hirarki Maslow. 
Tabel 3. Variasi Produk yang Tergolong setiap Level Hirarki Maslow

\begin{tabular}{l|l|l|l|l|l}
\hline \multicolumn{1}{c|}{ Produk } & $\begin{array}{l}\text { Psychological } \\
\text { Needs }\end{array}$ & Safety Needs & \multicolumn{1}{|c|}{ Love Needs } & Esteem Needs & \multicolumn{1}{c}{$\begin{array}{c}\text { Self } \\
\text { Actualization }\end{array}$} \\
\hline $\begin{array}{l}\text { Klat } \\
\text { Hanunikasi }\end{array}$ & $\begin{array}{l}\text { HP memiliki } \\
\text { fungsi dasar } \\
\text { saja yaitu } \\
\text { telephone dan } \\
\text { sms. }\end{array}$ & $\begin{array}{l}\text { HP resistant } \\
\text { air }\end{array}$ & $\begin{array}{l}\text { HP dilengkapi } \\
\text { fasilitas jejaring } \\
\text { sosial, misal bbm, } \\
\text { fb, whatsapp }\end{array}$ & $\begin{array}{l}\text { HP berlapis } \\
\text { permata }\end{array}$ & HP transparan \\
\hline $\begin{array}{l}\text { Alat } \\
\text { Transporta- } \\
\text { si } \\
\text { Mobil }\end{array}$ & $\begin{array}{l}\text { Mobil dengan } \\
\text { fungsi } \\
\text { standart }\end{array}$ & $\begin{array}{l}\text { Mobil } \\
\text { dilengkapi } \\
\text { sistem } \\
\text { keamanan \& } \\
\text { GPS }\end{array}$ & $\begin{array}{l}\text { Mobil warna } \\
\text { putih yang } \\
\text { memiliki club } \\
\text { pecinta mobil } \\
\text { warna putih }\end{array}$ & $\begin{array}{l}\text { Mobil branded } \\
\text { lamborghini }\end{array}$ & $\begin{array}{l}\text { Mobil bentuk } \\
\text { sepatu }\end{array}$ \\
\hline $\begin{array}{l}\text { Home } \\
\text { Kppliancess } \\
\text { Kursi }\end{array}$ & $\begin{array}{l}\text { Kursi fungsi } \\
\text { standart } \\
\text { sebagai } \\
\text { tempat duduk }\end{array}$ & $\begin{array}{l}\text { Kursi aman\& } \\
\text { kokoh } \\
\text { dengan bahan } \\
\text { yang kuat } \\
\text { dan handal }\end{array}$ & $\begin{array}{l}\text { Kursi yang } \\
\text { digunakan } \\
\text { sebagai tempat } \\
\text { diskusi yang } \\
\text { memuat banyak } \\
\text { pengguna }\end{array}$ & $\begin{array}{l}\text { Kursi branded } \\
\text { dengan harga } \\
\text { mahal }\end{array}$ & $\begin{array}{l}\text { Kursi unik } \\
\text { bentuk bola }\end{array}$ \\
\hline $\begin{array}{l}\text { Sandang } \\
\text { Pakaian }\end{array}$ & $\begin{array}{l}\text { Pakaian fungsi } \\
\text { standart untuk } \\
\text { melindungi } \\
\text { tubuh }\end{array}$ & $\begin{array}{l}\text { Pakaian anti } \\
\text { peluru, fire } \\
\text { resistant }\end{array}$ & $\begin{array}{l}\text { Pakaian seragam, } \\
\text { sarimbit. }\end{array}$ & $\begin{array}{l}\text { Pakaian branded } \\
\text { dengan harga } \\
\text { mahal }\end{array}$ & $\begin{array}{l}\text { Pakaian } \\
\text { berbahan kertas, } \\
\text { bubble plastik, } \\
\text { kulit binatang }\end{array}$ \\
\hline $\begin{array}{l}\text { Pangan } \\
\text { Makanan }\end{array}$ & $\begin{array}{l}\text { Makanan } \\
\text { pokok }\end{array}$ & $\begin{array}{l}\text { Makanan non } \\
\text { kolesterol } \\
\text { aman untuk } \\
\text { kesehatan }\end{array}$ & $\begin{array}{l}\text { Makanan dengan } \\
\text { ukuran besar }\end{array}$ & $\begin{array}{l}\text { Makanan } \\
\text { branded tertentu. }\end{array}$ & $\begin{array}{l}\text { Makanan unik } \\
\text { dan kreatif }\end{array}$ \\
\hline
\end{tabular}

Produk yang dirancang dan ditargetkan untuk memenuhi jenjang Maslow tertentu harus disesuaikan dengan keinginan pengguna pada setiap level. Sebagai contoh apabila akan dirancang produk handphone untuk memenuhi jenjang esteem need, maka dibutuhkan handphone yang berkualitas tinggi, canggih/modern dan hightech dengan harga mahal. Oleh karena itu, karakter setiap jenjang Maslow perlu diketahui.

Salah satu cara untuk mengidentifikasi karakter pengguna produk disetiap jenjang Maslow, yakni dengan menggunakan kata kansei. Kata kansei merupakan ekspresi dari keinginan konsumen yang diharapkan pada pada produk yang akan dipilih. Berbagai penelitian dikembangkan untuk mengidentifikasi kata kansei pada sebuah produk.Berdasarkan penelitian pendahulu dapat dirumuskan kata-kata kansei yang terdapat pada setiap produk seperti terlihat pada Tabel 4 .
Kata-kata kansei yang terdapat pada Tabel 4 dibentuk berdasarkan jenis produk yang telah disajikan pada Tabel 2.Tabel 4 menunjukkan bahwa berbagai jenis produk memiliki kata kansei yang merepresentasikan kebutuhan konsumen. Produkhandphone, mobil, kursi, pakaian, dan makanan memiliki beberapa kata kansei. Produk handphone memiliki 15 kata kansei ( Jiao, 2006) dan 13 kata kansei (Chen\&Hiu, 2007). Produk mobil terdiri dari 15 kata kansei (Hasio \& Wang, 1998).Produk kursi memiliki 20 kata kansei (Hasio\&Chen, 1997).Produk pakaian terdiri dari 34 kata kansei (Nagamachi, 2008).

Produk makanan memiliki 21 kata kansei (Sano \& Ueda, 2008). Kata - kata kansei pada setiap produk akan diklasifikasikan berdasarkan jenjang-jenjang kebutuhan Maslow seperti pada Tabel 5. Kata kansei tersebut dapat digunakan sebagai acuan dalam mengembangan produk untuk memenuhi jenjang Maslow tertentu.Tabel 5 
menunjukkan pengelompokan kata kansei menurut jenjang Maslow. Kata kansei diprosentasikan berdasarkan jenis produk disetiap level Maslow.Tabel 5 diperoleh dari hasil penyebaran kuisioner kansei kepada 53 konsumen yang kemudian diklasifikasikan berdasarkan jenjang Maslow. Proses klasifikasi masih bersifat subyektif. Metode klasifikasi yang objektif dan terukur perlu dirancang untuk pengembangan penelitian selanjutnya.
Pengembangan produk berdasarkan kebutuhan Maslow merupakan sebuah strategi untuk menarik konsumen. Manusia akan menuju jenjang berikutnya setelah memenuhi kebutuhan dasar. Oleh karena itu, pengembangan dan difersifikasi produk perlu diarahkan menuju jenjang kebutuhan Maslow agar produk tersebut mampu memuaskan penggunanya, maka perlu diidentifikasi kata kansei suatu produk.

Tabel 4. Identifikasi Kata Kansei Produk handphone, Mobil, Kursi, Pakaian, dan Makanan

\begin{tabular}{|c|c|c|c|c|}
\hline Handphone & Mobil & Kursi & Pakaian & Makanan \\
\hline $\begin{array}{l}\text { Portable } \\
\text { Sturdy } \\
\text { Enjoyable } \\
\text { Dignified } \\
\text { Cheerful } \\
\text { Natural } \\
\text { Delightfull } \\
\text { Stimulating } \\
\text { Comfortable } \\
\text { Dazzling } \\
\text { Mature } \\
\text { Fashionable } \\
\text { Friendly } \\
\text { Cute } \\
\text { Futuristik (Jiao, } \\
\text { 2006) } \\
\text { Fuctional } \\
\text { Handy } \\
\text { Cute } \\
\text { Flimsy } \\
\text { Modern } \\
\text { Thin } \\
\text { Innovative } \\
\text { Hightech } \\
\text { Durable } \\
\text { Fresh } \\
\text { Digital } \\
\text { Tren-pioneering } \\
\text { Chen\&Hiu, 2007) }\end{array}$ & $\begin{array}{l}\text { Delightfull } \\
\text { Eruptive } \\
\text { Young } \\
\text { Healthy } \\
\text { Home } \\
\text { High-grade } \\
\text { Well-bred } \\
\text { Dignified } \\
\text { Handy } \\
\text { City-featured } \\
\text { Lovely } \\
\text { Agile } \\
\text { Up-to-date } \\
\text { Practical } \\
\text { Speedy } \\
\text { (Hasio\&Wang, } \\
\text { 1998) }\end{array}$ & $\begin{array}{l}\text { Grand } \\
\text { High-grade } \\
\text { Prevelent } \\
\text { Compact } \\
\text { Comfortable } \\
\text { Practical } \\
\text { Elegant } \\
\text { Steady } \\
\text { Streamlined } \\
\text { Handy } \\
\text { Lovely } \\
\text { Sleek } \\
\text { Durable } \\
\text { Authoritative } \\
\text { Individualistic } \\
\text { Dynamic } \\
\text { Advance } \\
\text { Emotional } \\
\text { Characteristic } \\
\text { Dignified } \\
\text { (Hasio\&Chen, } \\
\text { 1997) }\end{array}$ & $\begin{array}{l}\text { Adorable } \\
\text { Appealing } \\
\text { Beautifull } \\
\text { Calm } \\
\text { Charming } \\
\text { Comfortable } \\
\text { Cool } \\
\text { Elegant } \\
\text { Georgeus } \\
\text { Impressive } \\
\text { Lively } \\
\text { Lovely } \\
\text { Preety } \\
\text { Professional } \\
\text { Refreshing } \\
\text { Relaxing } \\
\text { Sexy } \\
\text { Stylish } \\
\text { Boring } \\
\text { Old-fashioned } \\
\text { Chic } \\
\text { Classic } \\
\text { Creative } \\
\text { Cute } \\
\text { Fun } \\
\text { Futuristik } \\
\text { Luxury } \\
\text { Shophisticated } \\
\text { Surreal } \\
\text { Masculine } \\
\text { Mystic } \\
\text { Simple } \\
\text { Childish } \\
\text { Crowded } \\
\text { (Nagamachi, 2008) }\end{array}$ & $\begin{array}{l}\text { Souce color } \\
\text { Aroma } \\
\text { Overall-flavour } \\
\text { Spicy-flavour } \\
\text { Vegetable-flavour } \\
\text { Richness } \\
\text { Saltiness } \\
\text { Sweetness } \\
\text { Acidity } \\
\text { Pungency } \\
\text { Thicness } \\
\text { Overall-judgement } \\
\text { Apparent-softness } \\
\text { After-taste } \\
\text { Peculiarity } \\
\text { Wholetaste } \\
\text { Oil-likeness } \\
\text { Egg-flavour } \\
\text { Whole appearance } \\
\text { Colour } \\
\text { Texture } \\
\text { (Sano\&Ueda, 2008) }\end{array}$ \\
\hline
\end{tabular}


RATIH SETYANINGRUM, I.G. BAGUS BUDI DHARMA, DAN HEDDY SHRI AHIMSA-PUTRA $\$$ KATAKATA KANSEI PADA PRODUK BERBASIS BUDAYA UNTUK PEMENUHAN KEBUTUHAN MASLOW

Tabel 5. Pengelompokan Kata Kansei berdasarkan Level Hirarki Maslow

\begin{tabular}{|c|c|c|c|c|c|}
\hline Produk & $\begin{array}{c}\text { Psychological } \\
\text { Needs }\end{array}$ & Safety Needs & Love Needs & Esteem Needs & $\begin{array}{c}\text { Self } \\
\text { Actualization }\end{array}$ \\
\hline $\begin{array}{l}\text { Alat } \\
\text { Komu- } \\
\text { nikasi } \\
\text { Hand- } \\
\text { phone }\end{array}$ & $\begin{array}{l}\text { Functional }(7,27 \%) \\
\text { Handy }(7,64 \%) \\
\text { Natural }(0,55 \%) \\
\text { Digital }(3,45 \%)\end{array}$ & \begin{tabular}{|l|} 
Sturdy $(8 \%)$ \\
Comfortable(6,18\% \\
Portable $(8,55 \%)$ \\
Durable(7,45\%)
\end{tabular} & $\begin{array}{l}\text { Enjoyable }(3,27 \%) \\
\text { Cheerfull }(1,09 \%) \\
\text { Delightfull }(2,18 \%) \\
\text { Mature }(1,82 \%) \\
\text { Friendly }(2 \%)\end{array}$ & $\begin{array}{l}\text { Dignified }(0,55 \%) \\
\text { Modern(5,64\%) } \\
\text { Hightech }(7,82 \%) \\
\text { Trend-pionering } \\
(2,18 \%)\end{array}$ & $\begin{array}{l}\text { Stimulating }(0,55 \%) \\
\text { Dazzling(1,27\%) } \\
\text { Futuristik(2,18\%) } \\
\text { Flimsy(4,91\%) } \\
\text { Innovative(6,18\%) } \\
\text { Thin }(4,73 \%) \\
\text { Cute( } 0,91 \%)\end{array}$ \\
\hline $\begin{array}{l}\text { Alat } \\
\text { Trans- } \\
\text { portasi } \\
\text { Mobil }\end{array}$ & Handy (13\%) & $\begin{array}{l}\text { Agile }(8,47 \%) \\
\text { Speedy }(10,7 \%) \\
\text { Practical }(7,49 \%)\end{array}$ & \begin{tabular}{|l|} 
Delightfull(5,5\%) \\
Home(5,21\%) \\
Well-bred(12,1\%) \\
Lovely $(8,47 \%)$ \\
\end{tabular} & $\begin{array}{l}\text { High-grade }(5,9 \%) \\
\text { City-feature }(4,9 \% \\
\text { Up to date }(3,9 \%)\end{array}$ & $\begin{array}{l}\text { Eruptive }(0,98 \%) \\
\text { Young }(5,86 \%) \\
\text { Healthy }(7,82 \%)\end{array}$ \\
\hline $\begin{array}{l}\text { Home } \\
\text { Appli- } \\
\text { acess } \\
\text { Kursi }\end{array}$ & $\begin{array}{l}\text { Prevelent }(0,9 \%) \\
\text { Handy(3,8\%) }\end{array}$ & \begin{tabular}{|l|} 
Compact $(3,5 \%)$ \\
Comfortable(15\%) \\
Practical $(6,1 \%)$ \\
Steady $(11 \%)$ \\
Sleek $(4,9 \%)$ \\
Durable(13\%) \\
Dinamic $(6,1 \%)$ \\
\end{tabular} & $\begin{array}{l}\text { Grand }(1,2 \%) \\
\text { Lovely }(7,3 \%) \\
\text { Emotional }(0,3 \%)\end{array}$ & $\begin{array}{l}\text { High-grade(3,2\%) } \\
\text { Elegance }(9 \%) \\
\text { Authoritative }(0 \%) \\
\text { Dignified }(0,9 \%)\end{array}$ & $\begin{array}{l}\text { Streamlined(7\%) } \\
\text { Individualistic }(0,3 \%) \\
\text { Advance(2\%) } \\
\text { Charactheristhic }(4,9 \%\end{array}$ \\
\hline $\begin{array}{l}\text { Sandang } \\
\text { Pakaian }\end{array}$ & Simple $(4,61 \%)$ & $\begin{array}{l}\text { Comfortable(10,3\% } \\
\text { Cool }(4,61 \%) \\
\text { Lively }(1,1 \%) \\
\text { Relax(6,14\%) } \\
\text { Refreshing(2,85\%) } \\
\text { Fun(1,97\%) }\end{array}$ & $\begin{array}{l}\text { Calm }(3,51 \%) \\
\text { Charming(2,6\%) } \\
\text { Lovely }(5,7 \%)\end{array}$ & $\begin{array}{l}\text { Elegant }(5,04 \%) \\
\text { Luxury }(1,97 \%)\end{array}$ & \begin{tabular}{|l} 
Adorable(3,51\%) \\
Appealing $(7,89 \%)$ \\
Beautifull $(4,61 \%)$ \\
Impressive $(5,92 \%)$ \\
Preety $(1,32 \%)$ \\
Profesional $(2,19 \%)$ \\
Sexy $(0,22 \%)$ \\
Stylish $(5,92 \%)$ \\
Chic $(1,54 \%)$ \\
Creative $(3,51 \%)$ \\
Cute(1,32\%) \\
Futuristic $(3,73 \%)$ \\
\end{tabular} \\
\hline $\begin{array}{l}\text { Pangan } \\
\text { Makanan }\end{array}$ & $\begin{array}{l}\text { Overalflav }(9,6 \% \\
\text { Spicy,ve }(7,6 \%) \\
\text { Saltiness }(3,01 \% \\
\text { Sweetness }(6,6 \% \\
\text { Acidity }(1,92 \%) \\
\text { Pungency }(4,2 \% \\
\end{array}$ & $\begin{array}{l}\text { Oil-likeness }(1 \%) \\
\text { Egg-flavour }(2,19 \%) \\
\text { Wholwtaste }(11,8 \%)\end{array}$ & \begin{tabular}{|l|} 
Aroma $(8,49 \%)$ \\
Whole \\
appearance $(6,85 \%$ \\
Colour $(3,56 \%)$ \\
\end{tabular} & $\begin{array}{l}\text { Richness }(4,6 \%) \\
\text { Overall } \\
\text { judgement(3,01\% }\end{array}$ & $\begin{array}{l}\text { Texture }(7,67 \%) \\
\text { Thicness }(1,1 \%) \\
\text { Apparent } \\
\text { softness }(3,56 \%)\end{array}$ \\
\hline
\end{tabular}

Tabel5dapatdigunakansebagaireferensi penentuan kata kansei sebuah produk yang terdapat pada suatu jenjang kebutuhan Maslow. Sebagai contoh, produk handphone yang digunakan untuk pemenuhan jenjang esteem needs dengan prestise dan gengsi yang diunggulkan, maka digunakan kata kansei dignified, modern, higtech dan trend-pionery.
Kata kansei tersebut dapat dikembangkan lagi secara lebih mendalam dengan melakukan survey kepada 53 konsumen. Tabel 5 juga merupakan hasil survey konsumen yang menunjukkan prosentasi kata kansei pilihan konsumen pada produk handphone, mobil, kursi, pakaian dan makanan. 
Tabel 6. Urutan Prioritas Pemenuhan Kebutuhan Level Maslow

\begin{tabular}{l|l|l|l|l|l}
\hline Produk & Psychological Needs & Safety Needs & Love Needs & Esteem Needs & Self Actualization \\
\hline Handphone & $4,73 \%$ & $7,5 \%$ & $2 \%$ & $4,04 \%$ & $4,12 \%$ \\
\hline Mobil & $13 \%$ & $8,89 \%$ & $7,82 \%$ & $4,9 \%$ & $4,89 \%$ \\
\hline Kursi & $2,35 \%$ & $8,51 \%$ & $2,93 \%$ & $3,75 \%$ & $3,55 \%$ \\
\hline Makaian & $4,61 \%$ & $4,5 \%$ & $3,94 \%$ & $3,5 \%$ & $3,47 \%$ \\
\hline
\end{tabular}

Tabel 6 menunjukkan orientasi level maslow pada setiap produk. Produk handphone yang memenuhi level safety need sangat digemari masyarakat $(7,5 \%)$. Urutan berikutnya adalah psychological need, self actualization, esteem need, dan love belongness.

Produk handphone di Indonesia berada diatas level dasar Maslow. Hal ini dibuktikan dengan produk handphone yang memiliki fasilitas media jejaring sosial laris dipasaran. Penjualan tablet Android mencapai 121 juta unit, angka tersebut bertambah 53 juta dibanding penjualan tahun 2012.Sementara Apple hanya mampu menjual 70,4 juta unit iPad, naik 61, 4 juta dibanding penjualan tahun 2012 (Tribun, 2013). Produk tablet murah dengan fiture dan fasilitas yang sebanding lebih diminati oleh masyarakat Indonesia. Hal tersebut diatas menunjukkan bahwa produk yang dirancang berdasarkan pertimbangan budaya, kebutuhan maslow dan kemampuan daya beli masyarakat memiliki potensi sukses di pasar.

Produk mobil, kursi, pakaian, dan makanan secara berurutan berdasarkan level maslow disajikan pada Tabel 6. Produk mobil yang berada pada jenjang psychological needs, lebih digemari masyarakat dengan prosentasi sebesar 13\%. Mobil dengan kebutuhan dasar/fungsional yang mampu menampung penumpang. Untuk pasar Indonesia, mobil LCGC (Low Cost Green Car) yang mampu memuat banyak penumpang (seven seater) digemari masyarakat. Penjualan mobil di Indonesia pada tahun 2013 mengalami kenaikan sebesar 10,48\% yakni sebanyak 1.229.904 unit.Produk tersebut terdiri dari produk mobil MPV (Multiple Purpose Vehicle) dan LCGC (Low Cost Green Car) yang sesuai dengan karakteristik masyarakat. Mobil murah ramah lingkungan (LCGC) mengalami kenaikan penjualan sebesar 4,16\% (Gaikindo dalam Tempo, 2013).

Produk kursi pada jenjang safety needs lebih digemari masyarakat. Kursi dengan keamanan yang tinggi yang ditunjukkan dengan bahan material yang kuat dan berkualitas. Produk pakaian pada setiap jenjang Maslow memiliki selisih prosentase sedikit, prosentase terbesar ada pada jenjang psychological needs.Sedangkan pada produk makanan yang terdapat pada jenjang love needs/belongness.

\section{SIMPULAN}

Berdasarkan analisis tersebut diatas, kesimpulan yang diperoleh, yaitu (1) Produk berorientasi budaya ditentukan berdasar empat aspek budaya yaitu materi, perilaku, bahasa, dan ide gagasan. Klasifikasi kata kansei ditentukan dengan cara memilih produk budaya yang berada pada jenjang Maslow kemudian dipadukan dengan penelitian pendahulu sehingga dapat dipetakan kata kansei sesuai jenjang hirarki Maslow. (2) Produk handphone dan pakaian didominasi pada tingkat psychological need, mobil dan kursi pada tingkat safety needs, makanan pada tingkat love $\mathcal{E}$ belongness. (3) Pengembangan produk berdasarkan jenjang kebutuhan Maslow merupakan salah satu strategi untuk menarik konsumen. Hal tersebut dilakukan mengingat adanya kecenderungan manusia untuk menuju jenjang yang lebih tinggi dalam upaya pemenuhan kebutuhan hidupnya. 


\section{DAFTAR PUSTAKA}

Ahimsaputra HS(2013) Budaya bangsa, jatidiri dan integrasi nasional: sebuah teori. Kemendikbud.

Chen and Hiu(2007) Kansei design with crosscultural perspective usability and internationalization, $\mathrm{HCCI}$, 4756.

Gunaady (2011) Pengembangan desain kursi roda khusus pada lansia berdasarkan citra (image) produk dengan metode kansei enginerring. Universitas Muhammadiyah Surakarta.

Hasio and Chen (1997)A semantic and shape grammar based approach for product design.Elsevier Science 18: 275-296.

Hasio and Wang (1998) Appliying the semantic tranformation method to product form design. Elsevier Science, 19: 390-330.

Hsu SH, Chuang MC and Chang CC(2000) A semantic di!erential study of designers' and users' product form perception, International Journal of Industrial Ergonomics. 25:375-391.

Jiao and Helander (2006)A kansei mining system for affective design, Expert system with application.30(4).
Maslow A(1970)Motivation and Personality, NewYork : Harper and Row.

Noor NL, Lokman AM and Nagamachi M (2008) Applying kansei engineering to determine emotional signature of online clothing websites.Proceedings of the Tenth International Conference on Enterprise Information Systems, Volume HCI, Barcelona, Spain, June 12-16, 2008. 2007, ISBN 978-989-811140-1.

SchuttleS and Eklund J(2005)Design of rocker switches for work-vehicles-an application of Kansei Engineering, Applied Ergonomics, 36:557-567.

Tempo (2013) Angka dan data penjualan mobil murah, Tanggal akses 22 September.

Tribunews (2013) Penjualan tablet android sukses telikung iPad, tanggal akses 5 Maret.

Ueda,R, Araki,T, Sagara Y, Ikeda G and Sano C (2008)Modified Food Kansei Model to Integrate Differences in Personal Attributes betweenIn-house Expert Sensory Assessors and Consumer Panels.Food Sci, Technol. Res 14 (5): $445-456$. 